

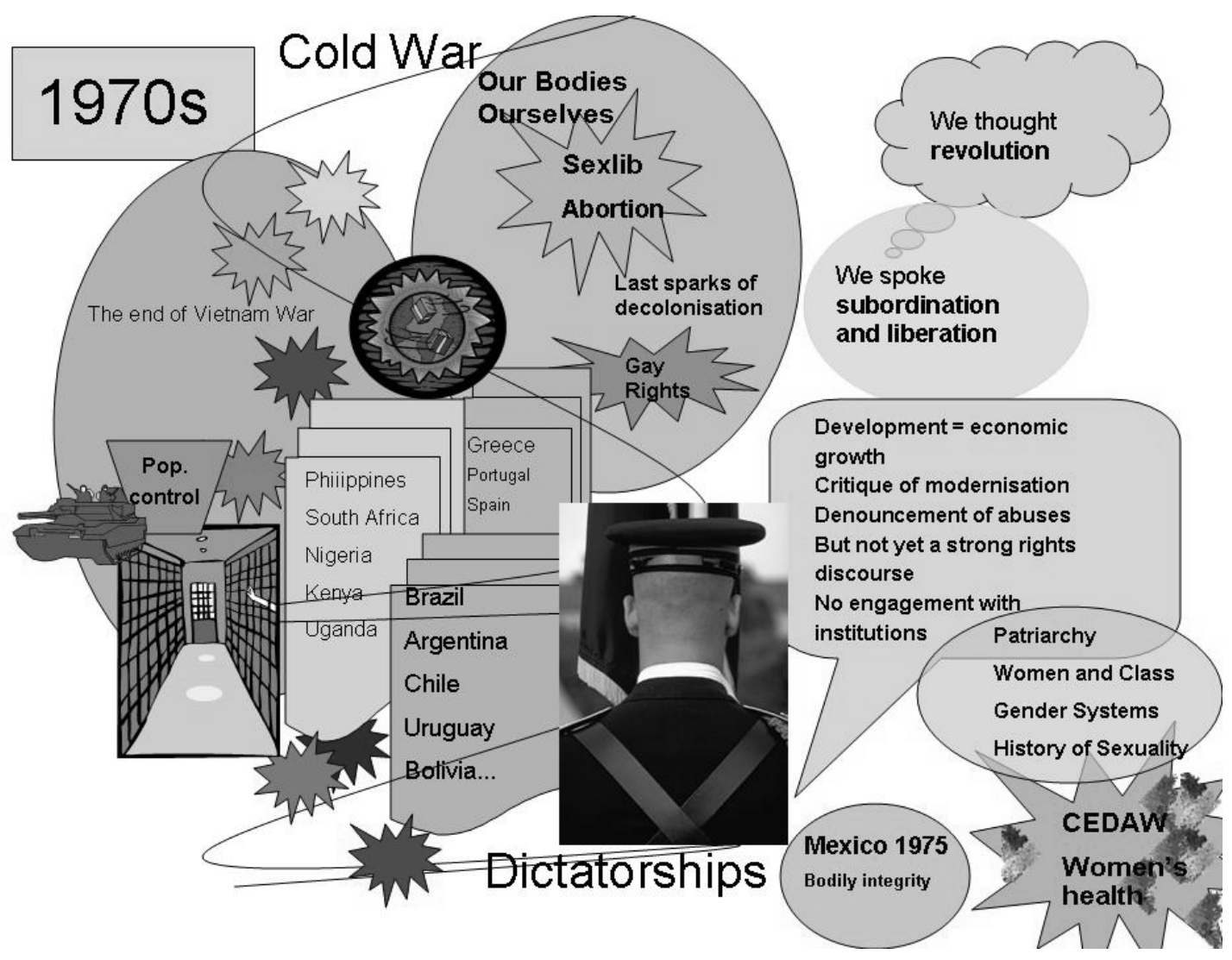

We will start with the 1970s: we can recall a global war (Vietnam), a few dictatorships (including in Europe), but at the same time key conceptual and political breakthroughs in the gender and sexuality field. This included a challenge to patriarchy as a legitimate system and, most importantly, the invention of the concept of sex/gender systems
(1974-5). To this we should also add the History of Sexuality by Foucault (1976-8), which remains a landmark of contemporary sex theorising. At the end of the decade, a key transformation would start in the development field with the adoption of the Washington Consensus, so-called because it immediately engaged the World Bank and the
International Monetary Fund (IMF). This advocated stringent cuts in public expenditures and greater emphasis on market forces as the main motor of development, along the lines of the economic reform adopted by the Thatcher administration in the UK. 


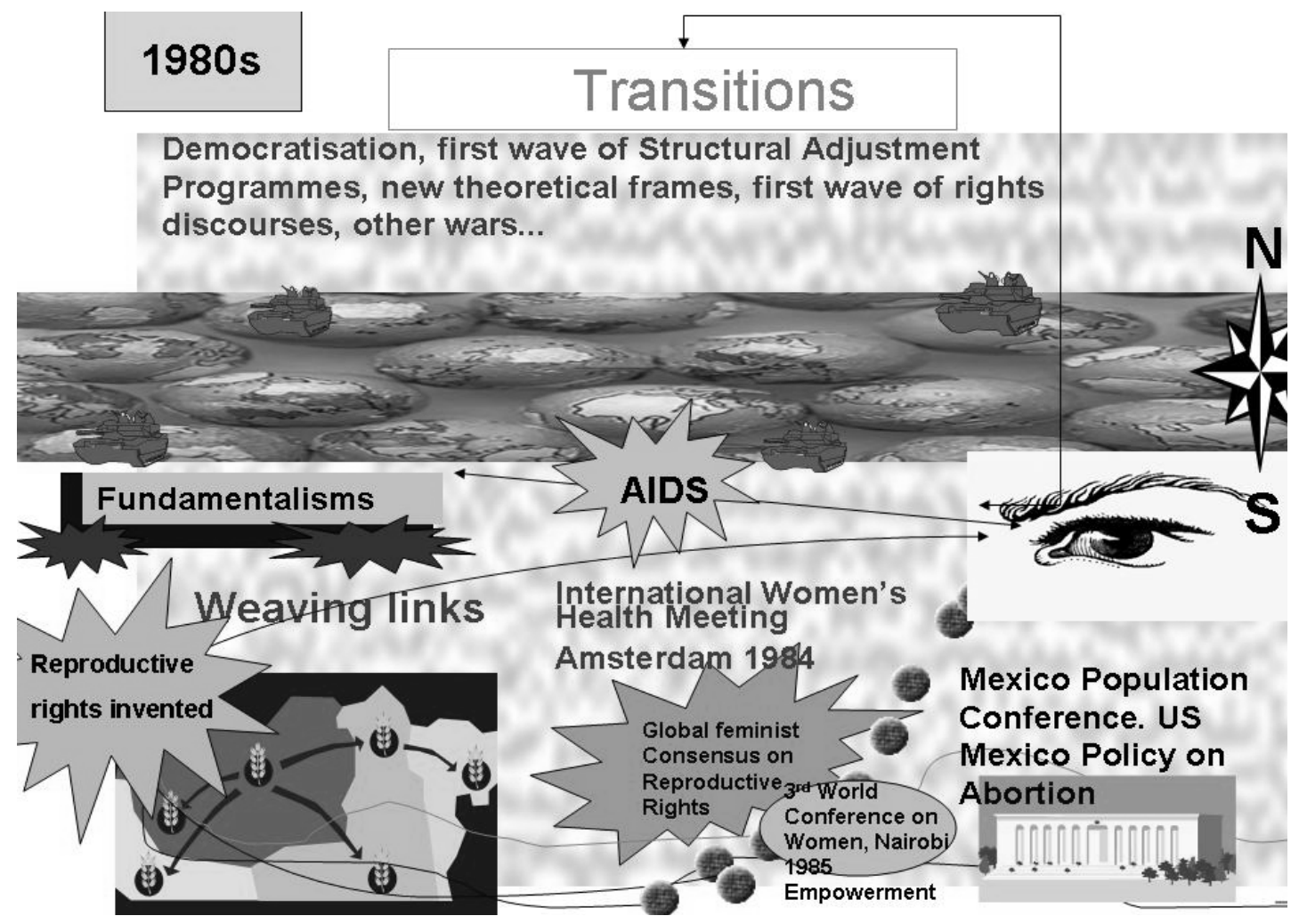

Then came the 1980s, a time of great transitions culminating in the fall of the Berlin Wall and Communist states in the former USSR in 1989. The gender and sexuality field took on broad new theoretical frames. This was also the time when we saw the emergence and rapid global expansion of HIV/AIDS. The Washington Consensus gained legitimacy and strength, while at the same time, connections were made across boundaries in respect to gender equality, reproductive rights, and to a lesser extent, sexuality related agendas. The key examples of this were the initial implementation of CEDAW (the Convention on the Elimination of All Forms of Discrimination Against Women), the Amsterdam Conference of 1984, in which a global feminist consensus was achieved with regard to the concept of reproductive rights, and the United Nations Third World Conference on Women, held in Nairobi in 1985. This was also a time of democratisation south of the Equator. In some contexts, for example in Latin America, the democratic struggles of the 1980s created space for public debate on abortion and the rights of 'sexual minorities'. 


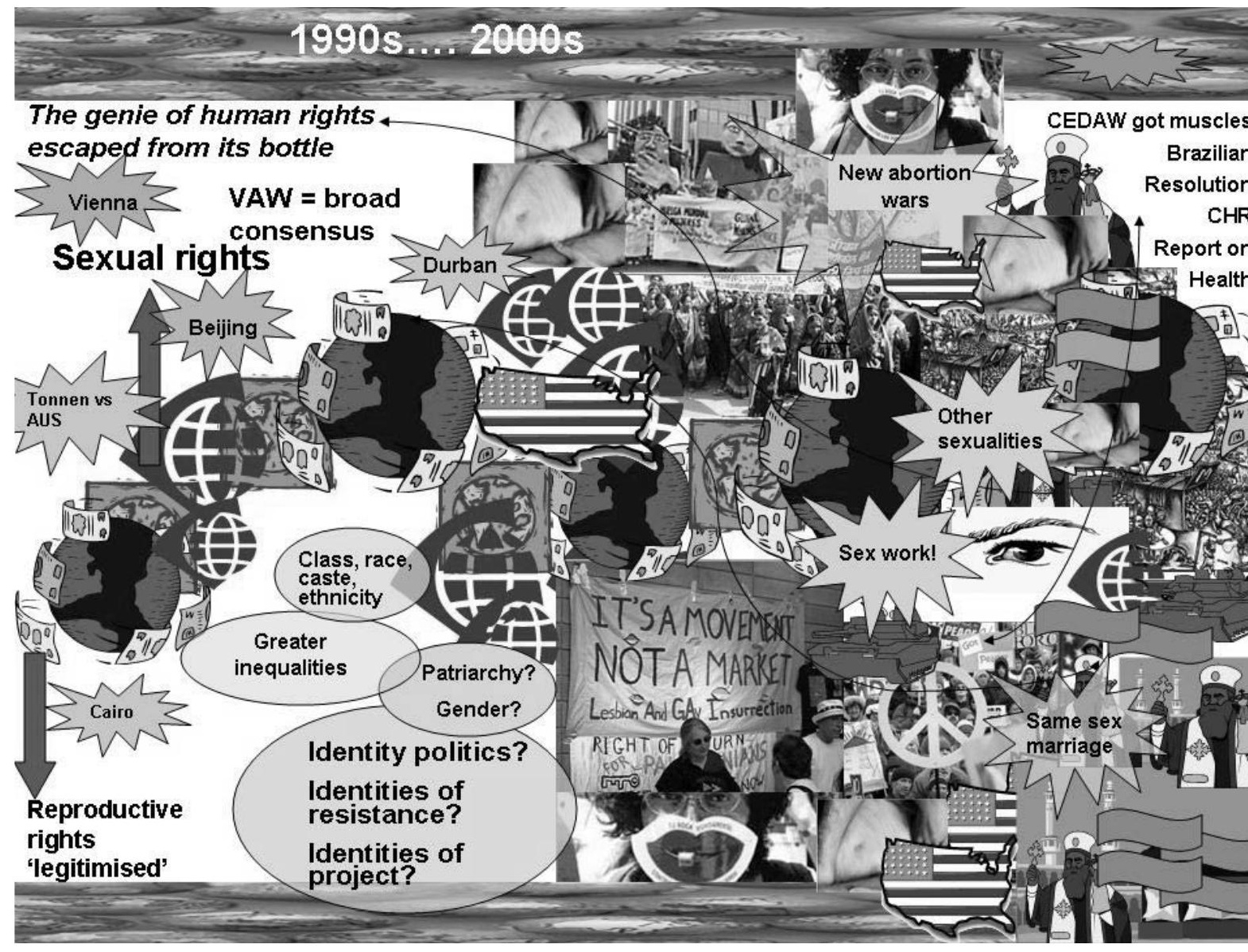

This takes us to the paradoxes of the 1990s and 2000s. Globalisation has intensified and within it we witnessed the continuation of market-oriented policy prescriptions. There has also been rapid growth in moral conservatism and fundamentalisms. However, optimistically, we have also experienced the positive expansion of transnational sexual politics. We have also seen the major policy breakthrough of the UN conferences (Vienna 1993; Cairo
1994; Beijing 1995) and the proliferation of local and global level struggles in relation to abortion, HIV and AIDS, and sexuality itself. 


\section{Sexuality and development}

The figures took us on a quick tour through the contemporary history of sexuality and sexual rights. The next step is to explore the connections between sexuality and development. This immediately raises major questions: what do we mean by development? What do we mean by sexuality?

\section{Development}

Is development the laundry list we can find in the 2006 Millennium Summit Document: investment, debt, trade, education, rural and agricultural development, employment, HIV and AIDS, malaria, tuberculosis and other health issues, gender equality, science and technology for development, migration. Or is it simply economic growth? Is it capitalism? Modernisation? Or should we say that development is the gradual expansion of modernity? Is it social progress (whatever this term may mean)? Or is it emancipation of self and of societies? Should development be the continuous effort to

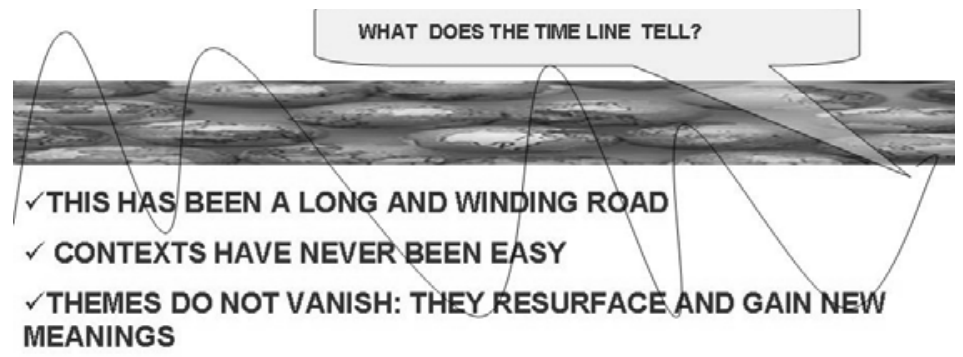

1990s-2000s

$\checkmark$ INTENSIFICATION AND ACCELARATION

$\checkmark$ GREATER INEQUALITIES, UNCERTAINTIES, RISK

$\checkmark$ NEW CONCEPTUAL FRAMES

$\checkmark$ GREATER INTELLECTUAL AND POLITICAL CONNECTIVTY GLOBAL $\checkmark$ RELIGION \> FUNDAMENTALISM

BOUNDED CULTURES $\gg$ MULTI-CULTURALISM. HYBRIDISM

construct societies and a global system based on democracy, social justice, human rights and expanding human capabilities?

\section{Sexuality}

Is sexuality the same as sex? Is it about anatomical differences? Does sexuality $=$ sex $=$ fixed and unchangeable biological drives (an essentialist view)? Or, on the

Postwar development discourses:

$\checkmark$ ECONOMICIST (MODERNISATION AND TRICKLE DOWN EFFECTS)

$\checkmark$ GENDER BLIND, GENDER NEUTRAL, GENDER BIASED

$\checkmark$ OPAQUE IN REGARD TO SEXUALITY

$\checkmark$ THE BEST EXAMPLE BEING 'POPULATION AND DEVELOPMENT DISCOURSE' contrary, do we understand sexuality as socially constructed by society, economics, politics and more (a constructivist view)? Is sexuality a universal feature of human experience? Or does it vary across history and culture?

\section{The time line}

How does development deal with sexuality? We find that development language regarding sexuality is far from transparent. Sexuality is never directly spoken about, yet it is here all the time. This is sharply illustrated by the population-development discourse. Since Thomas Malthus (English demographer and political economist) in the late eighteenth century, the main focus of population discourse has been fertility. Malthus spoke directly, although negatively, about sex. However, the discourses of population and development policies, which were put in place after the Second World War, did not talk about sex 


\section{GENDER}

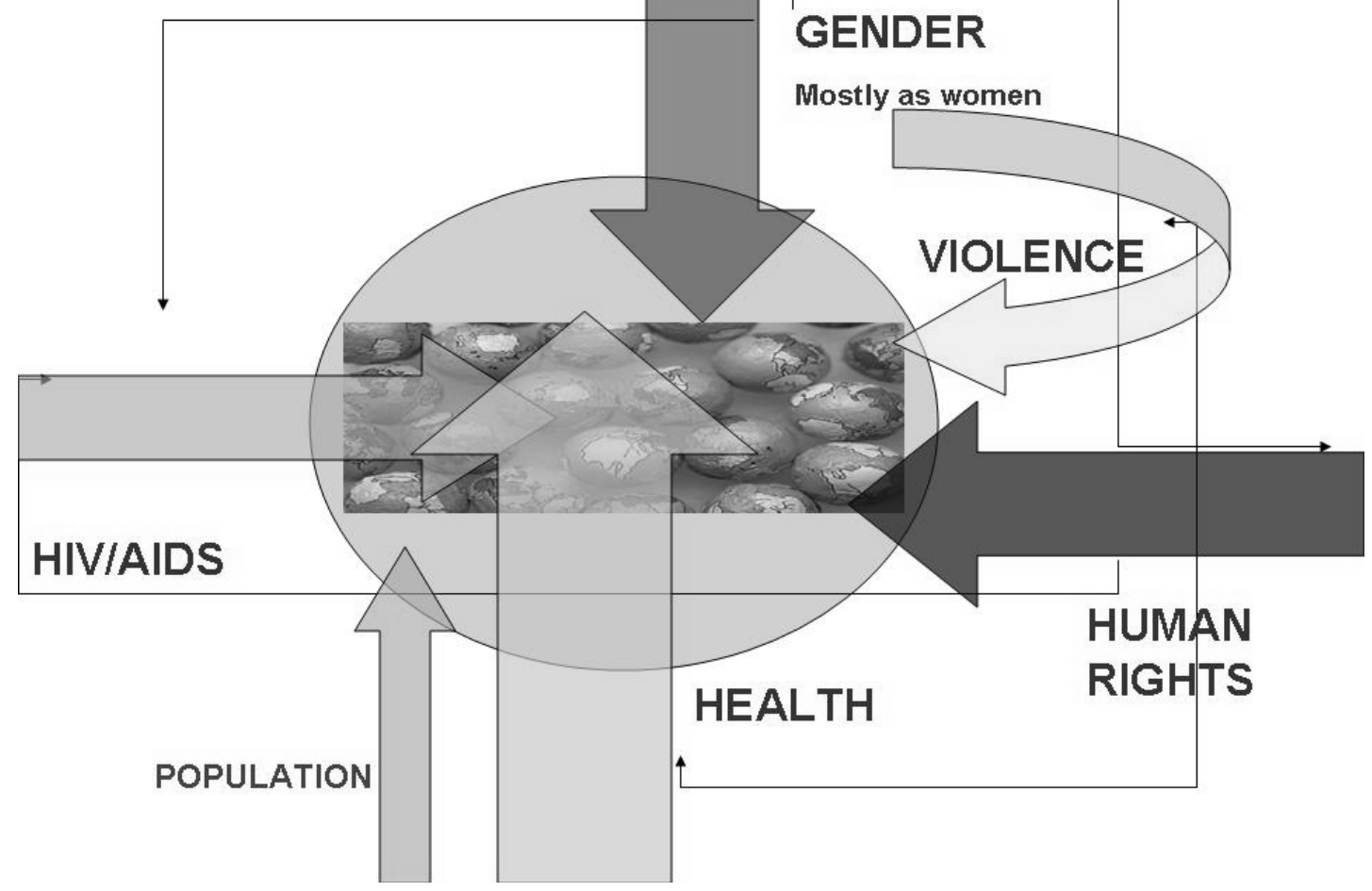

\section{Piercing the opacity}

Since the 1970s, we have gradually broken through these walls of silence, or opacity, around sexuality. This has occurred not so much at the level of theoretical frames, but in the more concrete area of policy, as an effect of both the HIV/AIDS epidemic and the 1990s UN negotiations concerning gender, and sexual and reproductive health and rights. In the complex and paradoxical scenario of the 1990s to 2000s, development has begun to recognise the significance of sexuality. This has also provoked a reaction by regressive forces, which aims to push sexuality back either out of sight or to the criminal margins. 
One obstacle to making a positive connection between sexuality and development is that often

development thinking - both

mainstream and progressive takes for granted conceptions that contemporary sexuality thinking would challenge. In particular, sex essentialism, i.e. the idea that sex is a given biological drive directed toward the reproduction of the species, remains an underlying assumption of conceptual frames and policy guidelines across development work. This contrasts sharply with the idea of sex as constructed which informs progressive contemporary sexuality thinking, research and advocacy.

One example of this is the radically different vision expressed by the development and sexuality fields with regard to 'health'. The field of development by and large regards public health interventions as positive elements of human development. However, critical theory on sexuality has looked at the ways the biomedical approach disciplines and regulates gender and sexuality, and both derives from and leads to discrimination, exclusion, stigma and even criminalisation.

The challenge is therefore to open up development discourse to more fully incorporate sexuality. At the same time, we must also recognise challenges in the area of sexuality itself, among them the need to consistently and persistently redefine, and refine, what we mean by sexual rights.

\section{PROGRESS HAS BEEN MADE}

BUT YET...

THE HARDCORE OF DEVELOPMENT DISCOURSE REMAINS UNTOUCHED

$\checkmark$ SEXUALITY IS VIEWED AS AN EXTERNALITY

$\checkmark$ ESSENTIALIST VIEW PREVAILS. SEXUALITY STILL SEEN AS A BIOLOGICAL DRIVE (NOT AS CONSTRUCTED BY SOCIETY, ECONOMICS, ETC.)

$\checkmark$ SEXUALITY IS: HETEROSEXUAL ADULTS HAVING SEX IN A NICE COUPLE'S BEDROOM... (OR TRANSGRESSION)

THE-GHALLENGE OF REFINING SEXUAL RIGHIS

DISTINGUISH AND ARTICULATE

$\checkmark$ GENDER AND SEXUALITY

$\checkmark$ HEALTH AND RIGHTS

$\checkmark$ REPRODUCTIVE AND SEXUAL

TO AVOID

$\checkmark$ FUSIONS AND CONFUSIONS

$\checkmark$ THE TENDENCY TO EMPHASISE THE NEGATIVE SIDES OF SEXUALITY (DISEASE, VIOLENCE AND ABUSE)

\section{PURSUE FURTHER CLARITY IN RESPECT OF:}

$\checkmark$ THE LIMITS AND POSSIBILITIES OF HUMAN RIGHTS DISCURSIVE REGIMES

$\checkmark$ BALANCE WITH RESPECT TO PROTECTION AND FREEDOM, STATE RESTRAINT AND/OR INTERVENTION

$\checkmark$ THE CROSS IMPLICATIONS OF SEXUALITY AND CRIMINAL LAW

$\checkmark$ THE ARTICULATION OF SEXUALITY, POVERTY, INEQUALITY

PRINCIPALLY, EXPOSE SEXUAL RIGHTS DISCOURSE TO THE TEST OF CONTEXTUALISATIONS:

CULTURE AND RELIGION

KINSHIP

CLASS, RACE, CASTE, ETHNICITY 


\section{Looking forward}

\section{Re-inventing social contracts}

The DAWN feminist network

(Development Alternatives with

Women for a New Era) looks at

how social values, norms,

institutions, structures and

practices determine the evolution

of different dimensions of human

rights. These dimensions include

the economic, political and

secular, as well as personal, in

respect to sexuality and

reproduction. So, how do we re-

invent social contracts in order to

realise sexual rights?

Struggle plays a central part in reinventing social contracts.

However, moments of collective agreement are equally important. We can regard these points of agreement as the defining moments of social contracts, which may be specific to a point in time, for example the birth of a nation state, the creation of its Constitution. But they can also be more diffuse, for example when social practices, such as gender equality and sexual autonomy, are recognised as legitimate dimensions of rights and justice. The making of agreements requires participation by different groups, to whom values, norms and roles within structures are assigned. ${ }^{1}$

\section{Crafting a political economy of sexuality}

Richard Parker (2001), writing about the HIV/AIDS epidemic, emphasises the role of structural violence - whether coming from globalisation trends, class, gender, race or ethnicity - in creating vulnerability. These factors must be systematically integrated into all discussions about sexuality. Altman (2001) speaks more directly of a political economy perspective that 'recognises the role of the state alongside concern for cleavages of class, gender, race: we need to think in terms of structures rather than specific issues or identities of sexuality'. Altman identifies four structural clusters which will determine the transformation of the current "sexscape" (landscape of human sexuality):

1 The economic

2 The cultural

3 The political (with emphasis on state regulation)

4 The epistemological (particular ways of understanding sexualities, human beings and the worlds they make).

He also praises the conceptual frame developed by Nancy Fraser (1997). This identifies three ways of connecting cultural meaning with an analysis of structures:

1 Recognition (of identities and difference)

2 Redistribution (of resources and power) and

3 Situatedness (retaining an idea of context).

These three principles can guide our frame for action.

FULFILMENT (DAWN)

OR, IF WE WANT

$\checkmark$ TO CRAFT A POLITICAL ECONOMY OF SEXUALITY THAT INCORPORATES HUMAN RIGHTS, ACKNOWLEDGES THE FLUIDITY AND INSTABILITY IN SEXUALITIES AND IS GUIDED BY POLITICS OF REDISTRIBUTION AND RECOGNITION (ALONG THE LINES DEVELOPED BY FRASER)

\section{THANK YOU!}




\section{Notes}

* Based on a presentation delivered at the 'Realising Sexual Rights' workshop, held at IDS, 28-30 September 2005

\section{References}

Altman, D. (2001) Global Sex, Chicago: University of Chicago Press

Foucault, Michel (1984) Histoire de la Sexualité 3: Le Souci de Soi, Paris: Gallimard

Foucault, Michel (1984) Histoire de la Sexualité 2:

L'Usage des Plaisirs, Paris: Gallimard
1 Revised excerpt from Re-inventing Social Contracts: The Promise of Human Rights - A Book Outline, by Gita Sen and Sonia Corrêa, mimeo, 2005.

Foucault, Michel (1976) Histoire de la Sexualité 1: La Volonté de Savoir, Paris: Gallimard

Fraser, N. (1997) Justice Interruptus, New York: Routledge

Parker, R. (2001) 'Sexuality, Culture and Power in HIV/AIDS Research', Annual Review of Anthropology, 30: 173-83 